\title{
Latent pulmonary function abnormalities in children with Crohn's disease
}

\author{
A. Munck*, D. Murciano**, R. Pariente**, J.P. Cezard*, J. Navarro*
}

Latent pulmonary function abnormalities in children with Crohn's disease. A. Munck, D. Murciano, R. Pariente, J.P. Cezard, J. Navarro. CERS Journals Ltd 1995.

ABSTRACT: Recently, latent pulmonary involvement has been described in adult patients with inflammatory bowel disease. It is unknown, however, whether this also occurs in children, and whether the pulmonary abnormalities differ between the acute phase and remission.

The incidence of pulmonary abnormalities has been investigated in 26 children with acute or quiescent Crohn's disease in terms of the following parameters: clinical pulmonary symptoms, chest roentgenograms and pulmonary function tests, including lung transfer factor for carbon monoxide (TLCO).

One child had a severe digital clubbing. Chest radiographs were normal in all subjects. No significant differences were found between acute and quiescent phase for pulmonary volumes and expiratory flows, but TLCO (\% predicted) was significantly decreased during the active phase of the disease as compared to remission $(53 \pm 15$ vs $81 \pm 19 \%$ predicted).

These data suggest that latent pulmonary involvement is also present in a paediatric population with active Crohn's disease, despite a short disease history and absence of smoking. Although the nature of this abnormality remains unclear, this extradigestive epiphenomenon should be taken into account with respect to the aetiopathogenesis of Crohn's disease.

Eur Respir J., 1995, 8, 377-380.
*Dept of Pediatric Gastroenterology and Nutrition, Hôpital Robert Debré, Paris, France. **INSERM U408, Clinique Pneumologique, Hôpital Beaujon, Clichy, France.

Correspondence: D. Murciano

Dept of Pneumology

Hôpital Beaujon

100 bd du Général Leclerc

92110 Clichy

France

Keywords: Paediatric Crohn's disease pulmonary function

Received: May 91994

Accepted after revision December 91994
Extradigestive manifestations frequently occur in inflammatory bowel disease (IBD). Among the latter, pulmonary involvement, such as bronchopulmonary suppuration [1, 2], granulomatous lung disease [3, 4], fibrosing alveolitis [5], diffuse panbronchiolitis [6], and sulphazalazine pneumonitis [7] have been described. Latent pulmonary involvement has also been observed in patients with IBD. Indeed, in patients free of clinical pulmonary manifestations and abnormalities of pulmonary function tests, abnormal chest radiographs or bronchoalveolar lavages have been reported [8-12]. These observations, however, have not been confirmed by other investigators [13, 14]. These discrepancies may be due to the fact that the above studies have included adult patients suffering from acute ulcerative colitis (UC) and Crohn's disease (CD), which are clinically and histologically distinct. Furthermore, these reports have essentially concerned patients with advanced disease who were already treated.

In the present study, we have investigated pulmonary function in 26 children during the acute or quiescent phase of Crohn's disease. All of them were nonsmokers and had no evidence of chronic bronchitis. Furthermore, some of them were studied during the initial phase of the disease (10 patients), thus avoiding any therapeutic interference.

\section{Methods}

\section{Patients}

Twenty six children with CD were studied after parental informed consent. Diagnosis of CD was established on standard clinical, radiological, endoscopic and/or histological criteria. There were 15 boys and 11 girls, 10-19 yrs of age (mean \pm SEM $14 \pm 3$ yrs). The small bowel alone was involved in six cases, the colon alone in 11 cases, and the localizations were multiple in nine patients. Crohn's disease activity was assessed by the Lloyd-Still index (LSI) [15]. The length of CD at the onset of the study ranged from the initial acute phase to $11 \mathrm{yrs}$. Four patients had previously undergone bowel surgery; others had received sulphasalazine $(n=4)$, or prednisolone $(n=10)$ within the past year.

Blood samples were collected for determination of haemoglobin levels.

Children, as well as parents, were questioned specifically about pulmonary symptoms, previous history of childhood pulmonary infection and drug treatment. A full clinical examination was performed as well as a standard chest radiograph. Pulmonary function tests were performed with the subjects in the sitting position. In 
each patient, the measurements of functional residual capacity (FRC) and total lung capacity (TLC) were made using a constant-pressure plethysmograph. Flowvolume curves were obtained with a Hewlett-Packard spirometer, in order to determine forced expiratory volume in one second $\left(\mathrm{FEV}_{1}\right)$ and forced vital capacity (FVC). The pulmonary carbon monoxide transfer factor (TLCO) was assessed using the steady-state method. The values of TLCO were expressed as the percentage of the normal value for gender, age and height [16] after correction for haemoglobin level according to reference equation [17].

The results are expressed as mean \pm SD. Statistical analysis was performed using Student's t-test for unpaired data.

\section{Results}

Using the LSI, we identified two groups of patients: 20 children (Group 1) were studied during the acute phase with individual values of LSI $<80$, and 10 children (Group 2 ) were studied in remission with individual values of LSI $>80$. Four children were studied both in the acute phase and in remission.

All children were free of clinical pulmonary symptoms; and none was a smoker. One child studied at the onset of the disease had a severe digital clubbing, which almost disappeared during remission. Clinical examination and chest radiograph were normal in all children.

The haemoglobin level was significantly $(\mathrm{p}<0.0001)$ lower in Group $1\left(11 \pm 2.1 \mathrm{~g} \cdot l^{-1}\right)$ than in Group 2 (13.8 \pm 1.1 $\left.\mathrm{g} \cdot l^{-1}\right)$ (tables 1 and 2 ).

Table 1. - Individual and mean \pm SD values of pulmonary function data and haemoglobin level of Group 1 patients studied during the active phase of Crohn's disease

\begin{tabular}{ccccccc}
\hline Pt & $\begin{array}{c}\text { FVC } \\
\text { No. }\end{array}$ & $\begin{array}{c}\text { FEV }_{1} \\
\%\end{array}$ pred & $\begin{array}{c}\text { FRC } \\
\%\end{array}$ & $\begin{array}{c}\text { TLC } \\
\%\end{array}$ & $\begin{array}{c}\mathrm{Hb} \\
\% \text { pred }\end{array}$ & $\begin{array}{c}\text { TLCo } l^{-1} \\
\% \text { pred }\end{array}$ \\
\hline $2 *$ & $70^{*}$ & 75 & 82 & $83^{*}$ & 8.8 & 40 \\
3 & 77 & 77 & 98 & 103 & 12.7 & 40 \\
4 & 81 & 90 & 99 & 95 & 12.5 & 65 \\
5 & 103 & 102 & 98 & 101 & 13.6 & 64 \\
6 & 97 & 99 & 105 & 99 & 6.5 & 56 \\
$7 *$ & $66^{*}$ & 66 & 77 & $58^{*}$ & 8.3 & 66 \\
8 & 106 & 113 & 108 & 98 & 13.4 & 57 \\
$10^{*}$ & $73^{*}$ & 80 & 76 & $82^{*}$ & 8.0 & 71 \\
11 & 94 & 83 & 157 & 112 & 12.5 & 50 \\
12 & 82 & 82 & 122 & 98 & 9.2 & 43 \\
13 & 77 & 88 & 90 & 91 & 13.0 & 56 \\
14 & 118 & 108 & 116 & 123 & 11.5 & 46 \\
15 & 82 & 89 & 98 & 95 & 10.2 & 37 \\
16 & 68 & 82 & 128 & 86 & 12.5 & 37 \\
17 & 89 & 97 & 106 & 91 & 12.0 & 49 \\
20 & 76 & 81 & 100 & 90 & 12.5 & 49 \\
22 & 85 & 98 & 114 & 105 & 10.8 & 76 \\
23 & 70 & 74 & 99 & 93 & 10.5 & 70 \\
24 & 91 & 87 & 95 & 97 & 9.4 & 44 \\
25 & 76 & 89 & 109 & 95 & 13.1 & 50 \\
\hline Mean \pm SD & $84+14$ & $88 \pm 12$ & $105 \pm 19$ & $94 \pm 14$ & $11 \pm 2$ & $53 \pm 15$ \\
\hline
\end{tabular}

Values are expressed as percentage of predicted $[16,17]$. Pt: patient; FVC: forced vital capacity; $\mathrm{FEV}_{1}$ : forced expiratory volume in one second; FRC: functional residual capacity; TLC: total lung capacity; Hb: haemoglobin; TLCo $†$ : corrected transfer capacity of the lungs for carbon monoxide. *: indicate the 3 patients (Group I) who exhibited a restrictive syndrome.
Table 2. - Individual and mean \pm SD values of pulmonary function data and haemoglobin level of Group 2 patients studied during remission

\begin{tabular}{|c|c|c|c|c|c|c|}
\hline $\begin{array}{l}\mathrm{Pt} \\
\text { No. }\end{array}$ & $\begin{array}{l}\text { FVC } \\
\% \text { pred }\end{array}$ & $\begin{array}{l}\mathrm{FEV}_{1} \\
\% \text { pred }\end{array}$ & $\begin{array}{l}\text { FRC } \\
\% \text { pred }\end{array}$ & $\begin{array}{l}\text { TLC } \\
\% \text { pred }\end{array}$ & $\begin{array}{l}\mathrm{Hb} \\
\mathrm{g} \cdot l^{-1}\end{array}$ & $\begin{array}{l}\text { TLco } † \\
\% \text { pred }\end{array}$ \\
\hline 1 & 82 & 79 & 109 & 96 & 14.6 & 60 \\
\hline 8 & 105 & 109 & 95 & 111 & 12.5 & 104 \\
\hline 9 & 97 & 105 & 91 & 100 & 14.9 & 60 \\
\hline 13 & 87 & 88 & 84 & 105 & 13.0 & 69 \\
\hline 16 & 78 & 88 & 103 & 106 & 13.7 & 79 \\
\hline 18 & 101 & 117 & 107 & 94 & 14.4 & 95 \\
\hline 19 & 104 & 94 & 85 & 91 & 16.1 & 73 \\
\hline 21 & 76 & 90 & 95 & 91 & 12.4 & 68 \\
\hline 23 & 82 & 87 & 99 & 101 & 14.1 & 120 \\
\hline 26 & 87 & 87 & 106 & 108 & 13.0 & 78 \\
\hline Mean & $90 \pm 11$ & $94 \pm 12$ & $97 \pm 9$ & $98 \pm 11$ & $3.8 \pm 1$ & $181 \pm 19$ \\
\hline
\end{tabular}

It should be noted that patients Nos. 8, 13, 16, and 23 were also studied during the active phase of Crohn's disease. Values are expressed as percentage of predicted [16, 17]. For abbreviations see legend to table 1 .

The individual and average lung function data are provided in tables 1 and 2 . Lung volumes were not significantly different between Groups 1 and 2, though three Group 1 children (Nos. 2, 7 and 10) exhibited a modest restrictive syndrome. In all other cases, the ventilatory variables were within normal limits.

During the active phase of disease (Group 1) the corrected values of TLCO were abnormally low, amount-ing to $53 \pm 15 \%$ of predicted normal [16]. In remission (Group 2 ), the corrected values of TLCO were significantly $(\mathrm{p}<0.0001)$ higher than in Group 1, amounting to $81 \pm$ $19 \%$ pred (fig. 1 and tables 1 and 2). In Group 2, however, there were still children with abnormally low TLCO $(<75 \%$ pred) $[16,18]$.

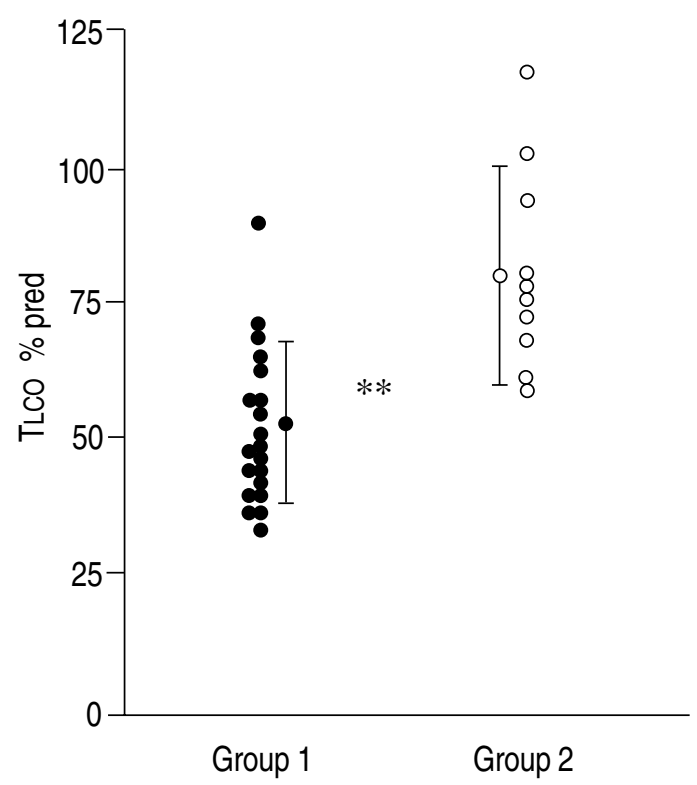

Fig. 1. - Individual and mean values $( \pm \mathrm{SD})$ of the corrected transfer factor of the lung for carbon monoxide (TLCO), expressed as percentage of predicted, of patients of Group 1 (closed circles), studied during the active phase of Crohn's disease, and of patients of Group 2 (open circles), studied during remission. ${ }^{* *}: \mathrm{p}<0.001$. 


\section{Discussion}

None of our patients had pulmonary symptoms. One child had a severe reversible digital clubbing at the onset of the disease, which disappeared during remission but reappeared during a recent exacerbation of the disease [19]. The incidence of digital clubbing varies markedly in the literature: CROHN and YARNIS [20] identified very few cases, but FIELDING and COOKE [21] found it in about $50 \%$ of their 181 patients. The pathogenesis of this sign remains unclear.

Paediatric reports of pulmonary symptoms in $\mathrm{CD}$ are very rare: HENRION et al. [5] described a bronchopulmonary suppuration with involvement of the lymph nodes in an 11 year old boy; PunTIs et al. [3] observed a symptomatic granulomatous lung disease in a 17 year old boy; and Teague et al. [22] described a 12 year old boy who developed a fatal progressive restrictive lung disease with a desquamative interstitial pneumonitis. In these paediatric case reports, respiratory function had not been evaluated.

The present study clearly confirms the high prevalence of impaired TLCO in CD, suggesting the presence of an interstitial pulmonary process. This interstitial involvement could not be identified by standard chest radiographs (computed tomographic (CT) scans and bronchoalveolar lavage have not been performed in our asymptomatic children). Based on spirometry, however, evidence of a restrictive lung process was observed in only three Group 1 children. Because of the age of our patients, the only technique available to study the lung gas transfer was the steady-state CO method [16]. Our TLCo data were compared to the results obtained in a normal population of young boys and girls studied with the same technique in our country, according to sex, age and height $[16,18]$. TLCO measurements may be affected by haemoglobin level but all the values were corrected according to the reference equations [17].

Three children studied during the acute phase (Group 1) exhibited a restrictive syndrome according to our definition (TLC $<85 \%$ pred), but there did not appear to be any relationship between TLCO values and disease severity.

We could find no previous reports of pulmonary function abnormalities in childhood $\mathrm{CD}$, and the results concerning adult patients are conflicting. Some authors found no difference in pulmonary function data in patients with inflammatory bowel disease and control groups [13, 14]. HeAtLey et al. [11] found abnormal lung function in about $50 \%$ of 102 patients with inflammatory bowel disease, including Crohn's disease and ulcerative colitis. The main finding of the present study was a reduced lung transfer factor not correlated with bowel disease site and activity, or concurrent drug administration mode. Similar results were found in studies performed by EADE et al. [9] and BonNiÈre et al. [10]. By contrast, PASQUIS et al. [8] found an increased functional residual capacity during the active phase of the disease, which was correlated with the $\mathrm{CD}$ activity index.

The nature of these transient changes in lung function remains unclear. Sulphazalazine is known to cause pulmonary parenchymal disease, such as hypersensitivity pneumonitis or alveolitis, but this does not appear to be the case in our patients because 10 of them were studied during the initial phase before initiation of therapy. There is increasing evidence that an immune system common to all mucosal surfaces exists, in which lymphocytes sensitized to antigens at one mucosal site may circulate and preferentially localize in the same or a different mucosal site. Indeed, experimental evidence for pulmonary damage by circulating immune complexes (CIC) in the pulmonary circulation has been provided [23]. Only one child in our population of patients, however, exhibited an elevated CIC level (unpublished data). It is possible that immune complexes can be detected only at specific times during the evolution of the disease.

Johnson et al. [13] and HeAthley et al. [11] failed to find a significant correlation between elevated CIC levels and pulmonary abnormalities. The role of circulating intestinal endotoxins [24] and/or excessive discharge of protease from inflammatory areas has also been described. BONNIÈRE et al. [10] and WALLAERT et al. [12] have studied bronchoalveolar lavage from CD patients free of clinical pulmonary symptoms. They found increased lymphocytic subpopulations; this alveolar lymphocytosis is a characteristic feature of granulomatous lung disorders, such as sarcoidosis [25]. Up to $70 \%$ of their patients had an increased spontaneous and/or stimulated superoxide anion production by alveolar macrophages, similar to that of circulating monocytes of CD [10]. The release of reactive material by macrophages may also play a role in the latent pulmonary involvement. However, this phenomenon can be excluded in our patients, because the serum angiotensin converting enzyme was below the normal range.

In conclusion, this study suggests an early involvement of the lung in paediatric Crohn's disease. The nature of this impaired TLCO merits further investigations.

\section{References}

1. Butland RJA, Cole P, Citron KM, Turner-Warwick M. Chronic bronchial suppuration and inflammatory bowel disease. Q J Med 1981; 197: 63-75.

2. Kraft SC, Earle RH, Roesler M, Esterly JR. Unexplained bronchopulmonary disease with inflammatory bowel disease. Arch Intern Med 1976; 136: 454-459.

3. Puntis JWL, Tarlow MJ, Raafat F, Booth IW. Crohn's disease of the lung. Arch Dis Child 1990; 65: 1270-1271.

4. Lemann M, Messing B, D'Agay F, Modigliani R. Crohn's disease with respiratory tract involvement. Gut 1987; 28: 1669-1672.

5. Henrion F, Bretagne MC, Neimann L, Flechon PE, Canton $\mathrm{Ph}$, Moeffer JC. Association exceptionnelle de lésions pulmonaires, cutanées et d'une iléite terminale chez un enfant de 11 ans. J Radiol 1982; 63: 123-126.

6. Desai SJ, Gephardt GN, Stoller JK. Diffuse panbronchiolitis preceding ulcerative colitis. Chest 1989; 95(6): 1342-1344.

7. Moss SF, Ind PW. Time course of recovery of lung function in sulphasalazine-induced alveolitis. Respir Med 1991; 85(1): 73-75. 
8. Pasquis P, Colin R, Denis Ph, Baptiste P, Galmiche JP, Hecketsweiler Ph. Transient pulmonary impairment during attacks of Crohn's disease. Respiration 1981; 41: 56-59.

9. Eade OE, Smith CL, Alexander JR, Whorwell PJ. Pulmonary function in patients with inflammatory bowel disease. Am J Gastroenterol 1980; 13: 154-156.

10. Bonnière $\mathrm{P}$, Wallaert $\mathrm{B}$, Cortot $\mathrm{A}$, et al. Latent pulmonary involvement in Crohn's disease: biological, functional, bronchoalveolar lavage and scintigraphic studies. Gut 1986; 27: 919-925.

11. Heathley RV, Thomas P, Prokipchuk EJ, Gauldie J, Sieniewicz DJ, Bienenstock J. Pulmonary function abnormalities in patients with inflammatory bowel disease. $Q J$ Med 1982; 203: 241-250.

12. Wallaert B, Colombel JF, Tonnel AB, et al. Evidence of lymphocyte alveolitis in Crohn's disease. Chest 1985; 87(3): 363-367.

13. Johnson NM, Mee AS, Jewell DP, Clarke SW. Pulmonary function in inflammatory bowel disease. Digestion 1978; 18: 416-418.

14. Neilly JB, Main ANH, Sharry C, Murray J, Russel RI, Moran F. Pulmonary abnormalities in Crohn's disease. Respir Med 1989; 83: 487-491.

15. Lloyd-Still JD, Green DC. A clinical scoring system for chronic inflammatory bowel disease in children. Dig Dis Sci 1979; 24: 620-624.

16. Chaussain M, Denjean A, Lebeau C, de Lattre J, Badonal J. Lung factor for CO in normal children by a steadystate method. Bull Eur Physiopathol Respir 1982; 18: 411-417.
17. Comroe JH Jr. Pulmonary diffusing capacity for carbon monoxide (DlCo). Am Rev Respir Dis 1975; 111: 225.

18. Quanjer PhH, Stocks J, Polgar G, Wise M, Karlberg J, Barsboom G. Compilation of reference values for lung function measurements in children. Eur Respir J 1989; 2 (supp. 4): 184-262.

19. Munck A, Priez PM, Pharaon I, Guran Ph, Navarro J. Maladie de Crohn chez un enfant présentant un hippocratisme digital. Arch Franc Ped 1991; 48: 590.

20. Crohn BB, Yarnis H. Regional iletis. 2nd revised edn. New York, Grune and Stratton, 1958.

21. Fielding JF, Cooke WT. Finger clubbing and regional enteritis. Gut 1971; 12: 442-444.

22. Teague WG, Sutphen JL, Fechner RE. Desquamative interstitial pneumonitis complicating inflammatory bowel disease of childhood. J Pediatr Gastroenterol Nutr 1985; 4: 663-667.

23. Brentjens JR, O'Conell DW, Pawloski IB, Hsu KC, Andres GA. Experimental immune complex disease of the lung: the pathogenesis of a laboratory model resembling certain human interstitial lung disease. J Exp Med 1974; 140: 105-125.

24. Colin R, Brancher T, Lemeland JF, et al. Recherche d'une endotoxinémie dans des enterocolites inflammatoires cryptogénétiques. Gastroenterol Clin Biol 1976; 3: $15-19$.

25. Smiejan JM, Cosnes J, Chollet Martin S, et al. Sarcoidlike lymphocytosis of the lower respiratory tract in patients with active Crohn's disease. Ann Intern Med 1986; 104: 7-21. 